\title{
Variable features of transient neonatal diabetes mellitus with paternal isodisomy of chromosome 6
}

\author{
E Marquis ${ }^{1}$, JJ Robert ${ }^{2}$, C Benezech ${ }^{3}$, C Junien ${ }^{1}$ and C Diatloff-Zito ${ }^{1}$ \\ ${ }^{1}$ INSERM U383, Hôpital Necker-Enfants Malades, Université de Paris V, France; ${ }^{2}$ Département de Pédiatrie et \\ M étabolisme, Hôpital Necker-Enfants Malades, Paris, France; ${ }^{3}$ Centre Hospitalier Louis Pasteur, France
}

\begin{abstract}
We describe two patients who suffered transient neonatal diabetes mellitus (TDNM), due to paternal isodisomy of chromosome 6. One patient, now 5 years old, had severe intra-uterine growth retardation, but recovered normal growth parameters. The other patient, currently 12 years old, had a normal birth weight but showed impaired post-natal growth; in addition to TNDM the patient presented with cardiac and thyroid abnormalities. These cases may suggest that the clinical phenotype of TNDM is more variable than previously believed. The contribution of genetic and epigenetic factors needs to be determined to elucidate the phenotype-genotype relationships of this disease. European Journal of Human Genetics
\end{abstract} (2000) 8, 137-140.

Keywords: neonatal diabetes mellitus; chromosome6 uniparental disomy; imprinting; intra-uterine growth; post-natal growth; developmental abnormalities

\begin{abstract}
Introduction
Neonatal diabetes mellitus (NDM) is a very rare entity with an estimated incidence of $1 / 400000-1 / 500000$ births in Europe. ${ }^{1}$ Neonates with NDM have an absolute requirement for insulin to maintain blood glucose. In about half of the NDM cases, the diabetes is transient (TNDM, MIM 601410). TNDM is frequently associated with intra-uterine growth retardation (IUGR) and very low adiposity. TNDM usually resolves before 6 months, but type-2 diabetes mellitus has been reported later in life. Chromosome6 duplications, ${ }^{2,3}$ and paternal uniparental disomy of chromosome6 (UPD6), isodisomy, have been described in patients with TNDM ${ }^{4,5} \mathrm{~A}$ candidate region on 6q23-q24 has been identified with an imprinted gene thought to be involved in the maturation of pancreatic beta-cells. ${ }^{6}$ We report two further cases of TNDM with paternal UPD6, with different growth patterns and clinical abnormalities.
\end{abstract}

\section{Patients and methods \\ Clinical report}

Two children were diagnosed with idiopathic TNDM. Table1 shows the main clinical features and laboratory findings.

Correspondence: Dr C Diatloff-Zito, INSERM U383, Hôpital

Necker-Enfants Malades, 149-161 rue de Sèvres 75743, Paris, Cedex 15, France. Tel: + 331444945 00; Fax: + 331478332 06;

E-mail: diatloff@necker.fr

Received 31 March 1999; revised 5 July 1999; accepted 5 August 1999
Child $A$ is the first child of unrelated parents of Moroccan origin, the younger sister is unaffected. The plasma glucose concentration was $5 \mathrm{mmol} / \mathrm{l}$, 5 hours after birth. Plasma insulin concentration was $<3 \mathrm{mU} / \mathrm{l}$ and plasma $\mathrm{C}$ peptide concentration $0.16 \mathrm{pmol} / \mathrm{l}$. Insulin was given intravenously at $0.15 \mathrm{mU} / \mathrm{kg} /$ day. After cessation of insulin, capillary blood glucose varied between 7 and $12 \mathrm{mmol} / \mathrm{l}$. Follow-up included glycated haemoglobin assays; oral glucose tolerance test and titrations of islet-cell antibodies (ICA, IAA, IA2, GAD) at 1, 2, and 4 years of age were in the normal range. Height and weight reached the main reference values curves by 1 year of age and have remained around this level since.

Child B is the fourth child of consanguineous parents of Moroccan origin. Three older siblings were unaffected. The newborn presented with vital distress requiring external cardiac stimulation. On the first day of life the child presented with hypotonia and seizures which were controlled with phenitoine. TNDM in patient B was associated with other severe pathological features (Table1). Statural growth is abnormal, height being $134 \mathrm{~cm}(-2 \sigma)$ and weight $25 \mathrm{~kg}(-2.5 \sigma)$ at age 10 years.

\section{Genotyping}

$10-20 \mathrm{ml}$ of peripheral blood were drawn from each patient and parents after they gave their informed consent. Genomic DNA was extracted from blood with the Nucleon BACC2 kit 
(Amersham Pharmacia Biotech SA, Orsay, France). For genotyping, microsatellite DNA markers ${ }^{7}$ were amplified. Genotypes were determined with either ${ }^{32} \mathrm{P}$-labelled primers or fluorescent primers analysed on an ABI 377 (Perkin Elmer, Applied Biosystems, Foster City, USA) automated sequencer with GeneScan and Genotyper softwares. Each PCR was carried out in a $25 \mu \mathrm{l}$ reaction mixture containing $20 \mathrm{ng}$ of genomic DNA, 20 pmol of each primer, 1-2 mM $\mathrm{MgCl}_{2}$, Taq polymerase buffer, $200 \mathrm{~mm}$ of each dNTP, and 0.2 unit of Taq polymerase (Gibco-BRL Life Technologies, Cergy Pontoise, France). Samples were amplified in 30 cycles of $20 \mathrm{~s}$ at $94^{\circ} \mathrm{C}$ for denaturing, $20 \mathrm{~s}$ at optimum annealing temperature, and $20 \mathrm{~s}$ at $72^{\circ} \mathrm{C}$ for extension, in a GeneAmp 9600 thermocycler (Perkin-Elmer). Alleles were separated by electrophoresis on a $5 \%$ denaturing polyacrylamide gel for 2.5 hours in a model ABI 377 DNA sequencer (Perkin-Elmer). For some markers, the genotype was determined by labeling one of the PCR primers with $\alpha{ }^{32} \mathrm{P}$-dATP by T4 polynucleotide kinase. PCR conditions were the same as those used for fluorescentlabelled markers.

\section{Results}

The results of genotyping with 21 microsatellite markers distributed along the whole of chromosome 6 are given in Figure1. The marker alleles were apparently homozygous all along chromosome 6 in both patients. The inherited alleles were of paternal origin with no maternal contribution evidence of a paternal UPD6. The paternal isodisomy is demonstrable at 10 loci for child $A$ and 14 loci for child $B$ (Figure1). Markers which were not fully informative were inherited in a pattern consistent with homozygosity for the paternal allele. Markers from other chromosomes including 20 markers on chromosomell (not shown), were inherited in a Mendelian mode. Routine karyotypes were normal.

\section{Discussion}

We report two new TNDM cases with paternal isodisomy of chromosome6. UPD6 has previously been reported to be associated with various clinical features such as complement deficiency, ${ }^{8}$ NDM with methyl malonic acidaemia and pancreatic $\beta$ cells agenesis, ${ }^{9}$ and TNDM with macroglossia. ${ }^{10}$ The association between TNDM and paternal UPD6 has been observed in at least six independent cases in various ethnic groups. ${ }^{4,5}$ These recent reports and our observation are in favour of the involvement of imprinted gene(s) on the chromosome region 6q23-q24. ${ }^{6}$ Chromosome6 paternal isodisomy is found in approximately $20-30 \%$ of patients with TNDM. It is thus a common genetic mechanism of the disease, but different from that involved in the BeckwithWiedemann and Prader-Willi/Angelman syndromes in which the UPD described are segmentary and located at the $11 p 15.5$ and 15q11-q13 imprinted domains, respectively. Paternal duplications of the 6q23-qter chromosomal region found in some patients with TNDM, ${ }^{2,3}$ suggest that a gain of function of a paternally expressed gene may be involved. Maternal UPD6 has been reported in two cases with no evidence of TNDM: ${ }^{11}$ once in a genome-screen linkage study, and once in HLA typing. ${ }^{11,12}$ The apparently low incidence of TNDM in the European population could be due to patients not requiring insulin therapy at birth going undiagnosed. ${ }^{13}$

Table 1 Clinical features and laboratory findings of patients with TNDM

\begin{tabular}{|c|c|c|}
\hline Clinical features & Patient A & Patient $\mathrm{B}^{\mathrm{a}}$ \\
\hline Sex & female & female \\
\hline Age (yr) & 5 & 12 \\
\hline Birth weight (g) & 1670 & 2800 \\
\hline (centile) & $<3 r d$ & 10th \\
\hline Birth length (cm) & 41.5 & 50 \\
\hline Birth head circumference $(\mathrm{cm})$ & 31 & 35 \\
\hline Gestation (weeks) & 41 & 41 \\
\hline Intra-uterine growth & retarded & mild retardation \\
\hline Placenta & calcified & oligoamnios \\
\hline Apgar score & 10 at $1 \mathrm{~min}$ & 3 at $1 \mathrm{~min}, 10$ at $10 \mathrm{~min}$ \\
\hline Infusion feeding & birth to $72 \mathrm{~h}$ & none \\
\hline Hyperglycaemia, dehydration & $\begin{array}{l}\text { day } 4: 9.5 \mathrm{mmol} / \mathrm{l} \\
\text { day } 10: 14-22 \mathrm{mmol} / \mathrm{l}\end{array}$ & 48 h: 19mmol/l \\
\hline Insulin interrupted at & 22 days & $2 \frac{1}{2}$ months \\
\hline Intellectual development & normal & school delay \\
\hline Postnatal growth & normal & slowed \\
\hline Diabetes relapse & no & no \\
\hline Cardiac & - & mitral insufficiency ${ }^{c}$ \\
\hline Other & - & $\beta$-thalassaemia major ${ }^{d}$ \\
\hline Diabetes in the family & none & IDDM NIDDM $^{\mathrm{e}}$ \\
\hline
\end{tabular}

The report on patient B of this paper is a reappraisal of a case previously reported as fortuitous UPD6 by Bittencourt MC et al ${ }^{12}$; ${ }^{b}$ diagnosed at 11 years, TSH $326 \mathrm{mmol} / \mathrm{L}$, free T4 $0.4 \mathrm{pmol} / \mathrm{L}$ (puffed-up face, cold intolerance, astheny), treated with L-thyroxine; ' $\mathrm{Mitral}$ valvular insufficiency, with left ventricular dilatation, diagnosed at 8 years, treated with captopril; ${ }^{d}$ Beta-thalassaemia diagnosed at $4 \frac{1}{2}$ years, required blood transfusions, deferoxamine infusion, a splenectomy at 10 years; ${ }^{\mathrm{M}}$ Maternal grandmother with IDDM, maternal grandfather with DNID. 


\section{Genotype}

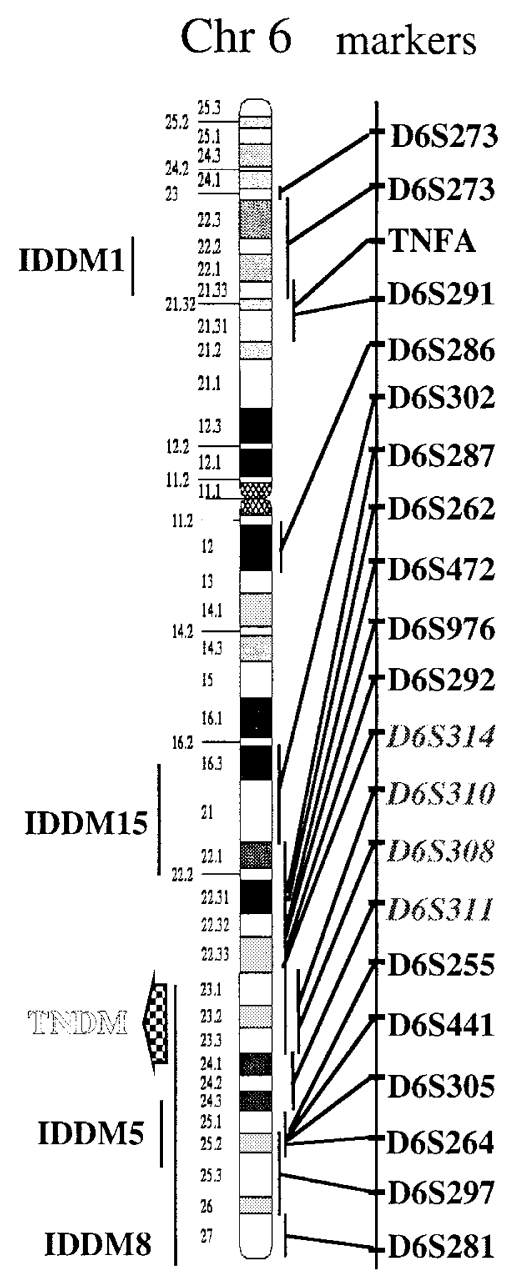

Family A
Family B

$\begin{array}{llllll}\mathbf{C} & \mathbf{M} & \mathbf{F} & \mathbf{C} & \mathbf{M} & \mathbf{F} \\ 2,2 * & 1,1 & 2,1\end{array}$

$3,3 * 1,2 \quad 1,3$

$2,2 * 1,3 \quad 4,2$

$4,4 * 1,23,4$

$2,2 * 1,3 \quad 2,2$

$3,3 \quad 2,3 \quad 1,3$

$3,3 * 2,2 \quad 1,3$

$2,2 * 1,13,2$

$2,2 * 1,3,3,2$

$1,1 * 2,23,1$

$2,2 \quad 2,3 \quad 1,2$

$\begin{array}{lll}2,2 & 1,2 & 2,2\end{array}$

$1,1 * 3,4 \quad 2,1$

$\begin{array}{llll}2,2 & 1,1 & 2,2\end{array}$

$1,1 * 3,4 \quad 2,1$

$1,1 * 3,3 \quad 2,1$

2,2 1,2 3,2

$2,2 \quad 1,2 \quad 1,2$

$1,1 \quad 1,2 \quad 2,1$

$\begin{array}{llll}2,2 & 1,2 & 1,2\end{array}$

$\begin{array}{llll}3,3 & 1,2 & 3,3\end{array}$
$1,1 * 3,3 \quad 1,2$

$3,3 * 1,4 \quad 2,3$

$3,3 * 1,2 \quad 3,1$

$\begin{array}{lll}1,1 & 2,2 & 1,1\end{array}$

$1,12,2 \quad 1,1$

$\begin{array}{lll}1,1 & 1,2 & 1,1\end{array}$

$\begin{array}{llll}1,1 & 2,3 & 1,1\end{array}$

$3,3 * 1,2 \quad 3,4$

$2,2 * 1,3 \quad 2,4$

$2,2 * 1,1 \quad 2,1$

$3,3 * 1,1 \quad 3,2$

$2,2 * 1,1 \quad 2,3$

$4,4 * 1,3 \quad 4,2$

$1,1 * 2,2 \quad 1,2$

$3,3 * 1,2 \quad 3,3$

$4,4 * 2,3 \quad 4,1$
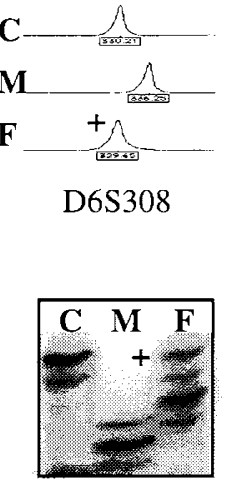

D6S310

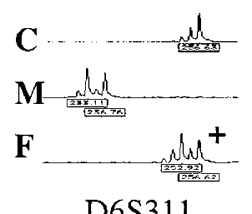

D6S311

TNFA

\section{UPD6 patterns}

Family A

Family B
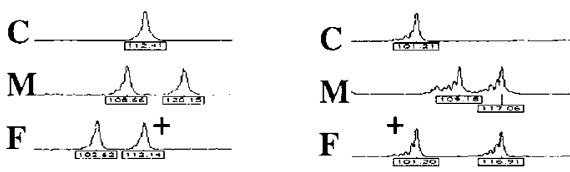

TNFA
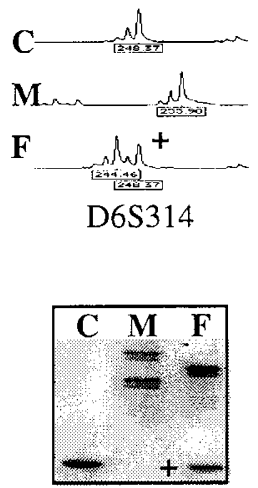

D6S310

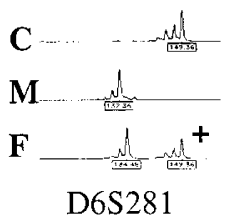

Figure 1 Genotype for 21 chromosome 6 microsatellite markers of patients with TNDM. Paternal haplotype transmitted in bold. Right part: alleles of representative markers in families A and B, Genotyper sample analysis for all the markers except D6S310 (autoradiography). Patient A (TNF $\alpha$, D6S308, D6S310, D6S311), patient B (TNF $\alpha$, D6S314, D6S310, D6S281). The affected daughter in both families has inherited only paternal alleles. The inherited paternal allele is indicated by + . Symbols: (C): affected child; $(M)$ : mother; $(F)$ : father. Left part: chromosome6 ideogram, cytogenetic location of markers and of loci predisposing to insulin dependent diabetes mellitus (IDDM, type 1 diabetes), IDDM1, IDDM5, IDDM8, IDDM 15, as well as the candidate region of the TNDM locus (markers in italic).

IUGR and low birth weight in TNDM could result from the lack of insulin as a growth factor in utero. It would be valuable to identify genes participating in birth weight control, since low birth weight is a condition that reduces perinatal survival and increases the risk of cardiovascular disease, and type 2 diabetes in adult life. ${ }^{14}$

TNDM in patient $A$ is typical of "classic TNDM, ${ }^{15}$ after 5 years she is healthy. Patient $B$ had impaired statural and ponderal post-natal growth and other pathological features (cardiac anomalies and hypothyroidism) in addition to TNDM. Although hypothyroidism may be due to complications of major $\beta$ thal assaemia, ${ }^{16}$ there are alternative possible explanations: unmasking of an autosomal recessive mutation due to the chromosome 6 isodisomy, or consanguinity of the parents resulting in a recessive disorder. Other mechanisms such as i) a multiendocrine alteration process, ii) imbalance in signalling, iii) imprinting effects (target tissue, variable tissue responses to stimuli, the mutation type, and the parental origin of the allele which bears the mutation), are also possible.

Further investigations are needed to identify the clinical spectrum of TNDM, its genetic and molecular basis, and to evaluate its impact on more common forms of diabetes such as non insulin-dependent diabetes mellitus (NIDDM). 


\section{Acknowledgements}

We thank $\operatorname{Dr} C$ Turleau for discussions, and the Centre National de la Recherche Scientifique. This research was funded by grants from the Fondation de France and the Institut National de la Santé et de la Recherche Médicale. EM is a recipient of the French Ministère de I'Education Nationale, de la Recherche et de la Technologie fellowship. We thank Mathilde Varret and Olivier Gribouval for their help with automatic sequencing and genotyping technologies.

\section{References}

1 von Mühlendahl KE, Herkenhoff $\mathrm{H}$ : Long-term course of neonatal diabetes. N Engl J Med 1995; 333: 704-708.

2 Ziel B, Zneimer SM, Bachman R: Partial trisomy of chromosome6q. An interstitial duplication of the long arm. Am J Hum Genet 1995; 53: A131.

3 Arthur El, Zlotogora J, Lerer I et al: Transient neonatal diabetes mellitus in a child with invdup(6)(q22q23) of paternal origin. Eur J Hum Genet 1997; 5: 417-419.

4 Temple IK, James RS, Crolla J et al: An imprinted gene(s) for diabetes? Nat Genet 1995; 9: 110-112.

5 Whiteford ML, Narendra A, White MP et al: Paternal uniparental disomy for chromosome6 causes transient neonatal diabetes. J Med Genet 1997; 34: 167-168.

6 Gardner RJ, Mungall AJ, Dunham I et al: Localisation of a gene for transient neonatal diabetes mellitus to an $18.72 \mathrm{CR}_{3000}(5.4 \mathrm{Mb})$ interval on chromosome6q. J Med Genet 1999; 36: 192-196.
7 Dib C, Fauré C, Fizames D et al: A comprehensive genetic map of the human genome based on 5,264 microsatellites. Nature 1996; 380: 1-5.

8 Welch TR, Beischel LS, Choi E, Balakrishnan K, Bishof NA: Uniparental isodisomy 6 associated with deficiency of the fourth component of complement. J Clin Invest 1990; 86: 675-678.

9 Abramowicz MJ, Andrien M, Dupont E et al: Isodisomy of chromosome6 in a newborn with methylmalonic acidemia and agenesis of pancreatic beta cells causing diabetes mellitus. J Clin Invest 1994; 94: 418-421.

10 Christian SL, Rich BH, Loebl C et al: Significance of genetic testing for paternal uniparental disomy of chromosome 6 in neonatal diabetes mellitus. J Pediatr 1999; 134: 42-46.

11 Van den Berg-Loonen EM, Savelkoul P, van Hooff $H$ et al: Uniparental maternal disomy 6 in a renal transplant patient. Hum Immunol 1996; 45: 46-51.

12 Bittencourt MC, Morris MA, Chabod J et al: Fortuitous detection of uniparental isodisomy of chromosome6. J Med Genet 1997; 34: 77-78.

13 McGill JJ, Roberton DM: A new type of diabetes mellitus of infancy? Arch Dis Child 1986; 61: 334-336.

14 McCarthy M: Weighing in on diabetes risk. Nat Genet 1998; 19: 209-210.

15 Gardner RJ, Robinson DO, Lamont L, Shield JPH, Temple IK: Paternal uniparental disomy of chromosome6 and transient neonatal diabetes mellitus. Clin Genet 1998; 54: 522-525.

16 Low LC: Growth, puberty and endocrine function in betathalassemia major. J Pediatr Endocrinol Metab 1997; 10: 175-184. 